DOI: https://doi.org/10.24127/ajpm.v10i2.3486

\title{
MODEL PEMBELAJARAN VIRTUAL FLIPPED CLASSROOM: EFEK PADA MOTIVASI DAN KINERJA KALKULUS MAHASISWA
}

\author{
Arbain $^{1 *}$, Fitriyani Hali ${ }^{2}$ \\ ${ }^{1 *, 2}$ Universitas Sembilanbelas November Kolaka, Kolaka, Indonesia \\ *Corresponding author \\ E-mail: $\quad \quad_{\text {abughazwanalhasan@gmail.com }}{ }^{\text {*) }}$
}

Received 18 January 2021; Received in revised form 29 June 2021; Accepted 01 July 2021

\begin{abstract}
Abstrak
Penelitian ini bertujuan untuk mengetahui keefektifan dari penerapan model pembelajaran Virtual Flipped Classroom (VFC) ditinjau dari motivasi dan kinerja kalkulus mahasiswa. Jenis penelitian ini adalah kuantitatif dengan desain one group pretest-posttest design. Penelitian ini dilakukan di Prodi Teknik Sipil Fakultas Sains dan Teknologi Universitas Sembilanbelas November Kolaka. Sampel dari penelitian ini adalah mahasiswa yang mengikuti mata kuliah kalkulus I sebanyak 28 orang. Untuk mengitahui keefektifan model VFC terhadap kinerja kalkulus mahasiswa menggunakan uji paired sample t-test. Sedangkan untuk mengetahui keefektifan motivasi menggunakan uji MANOVA satu arah. Uji normalitas data menggunakan Shapiro Wilk dan uji homogenitas data menggunakan Lavene Test turut disertakan sebagai uji asumsi. Hasil analisis data menunjukkan bahwa rata-rata skor motivasi mengalami peningkatan yang signifikan setelah penerapan model VFC. Demikian pula dengan variabel kinerja kalkulus mahasiswa, hasil uji t menunjukkan terdapat perbedaan yang signifikan antara rata-rata skor kinerja kalkulus mahasiswa sebelum dan sesudah penerapan model VFC. Model pembelajaran VFC efektif terhadap motivasi dan kinerja kalkulus mahasiswa. Motivasi dan kinerja kalkulus mahasiswa meningkat secara signifikan setelah penerapan VFC dengan kriteria peningkatan sedang.
\end{abstract}

Kata Kunci : Kinerja kalkulus; motivasi; virtual flipped classroom.

\begin{abstract}
This study aims to determine the effectiveness of the application of the Virtual Flipped Classroom (VFC) learning model in terms of student motivation and calculus performance. This type of research is quantitative with one group pretest-posttest design. This research was conducted at the Civil Engineering Study Program, Faculty of Science and Technology, Universitas Sembilanbelas November Kolaka. The sample of this study was 28 students programming the calculus I course. To determine the effectiveness of the VFC model on student calculus performance using the paired sample t-test. Meanwhile, to determine the effectiveness of motivation using the one-way MANOVA test. The data normality test used the Shapiro Wilk and the data homogeneity test used the Lavene Test were also included as an assumption test. The results of the data analysis show that the average motivation score has increased significantly after the application of the VFC model. Likewise, with the student calculus performance variable, the t-test results showed that there was a significant difference between the average calculus performance scores of students before and after the application of the VFC model. The VFC learning model is effective for student motivation and calculus performance. Students' motivation and calculus performance increased significantly after the application of VFC with moderate improvement criteria.
\end{abstract}

Keywords : Calculus performance; motivations; virtual flipped classroom.

\section{PENDAHULUAN}

Mempersiapkan mahasiswa agar memiliki kompetensi akademik sesuai kebutuhan masyarakat dunia abad 21 merupakan sebuah keharusan di tengah meroketnya teknologi informasi dan komunikasi. Salah satu kompetensi yang perlu dimiliki mahasiswa adalah keterampilan dan pengetahuan khususnya bidang science, technology, 
engineering, and mathematics (STEM) (Lee, 2011). Matematika memainkan peran penting dalam memajukan perkembangan individu dan masyarakat (Lo et al., 2017). Salah satu materi matematika dasar yang harus dikuasai oleh mahasiswa sebagai penunjang karir mereka dalam bidang STEM adalah kalkulus (Pearson \& Miller, 2012). Namun, masalah sekaligus tantangan dalam mata kuliah ini terjadi jauh sebelum mahasiswa memulai perjalanan kursus mereka di bidang STEM (Shodikin, 2017).

Kinerja kalkulus pelajar tidak mencerminkan pemahaman yang sebenarnya, baik di tingkat sekolah menengah maupun di perguruan tinggi (Ario \& Asra, 2018). Meskipun telah mengidentifikasi kesenjangan ini, banyak kampus terus menggunakan metodologi pembelajaran tradisional yang berfokus pada dosen dari pada mahasiswa, sehingga menghambat pengembangan keterampilan penting yang diperlukan di tempat kerja (Pelger $\&$ Nilsson, 2018).

Masalah dan tantangan tersebut semakin diperparah dengan merebaknya Covid-19 belakangan ini, yang mengharuskan dosen untuk migrasi dari pembelajaran tatap muka ke pembelajaran online. Hasil wawancara dengan mahasiswa prodi teknik sipil Universitas Sembilanbelas November kolaka menunjukkan bahwa perkuliahan kalkulus secara online cenderung lebih sulit memahami materi dari pada perkuliahan tatap muka. Selain itu, mahasiswa merasa tidak menikmati perkuliahan online sehingga berdampak pada motivasi belajar. Strategi perkuliahan yang masih berpusat pada dosen dan konten perkuliahan yang biasa-biasa saja menjadi penyebab utama masalah tersebut.
Untuk mengatasi masalah tersebut kemitraan peneliti pendidikan abad 21 telah menawarkan beberapa strategi pembelajaran yang berfokus pada kerangka kerja pembelajaran konseptual dan berorientasi pada keterampilan yang diperlukan bagi mahasiswa untuk berhasil dalam masyarakat digital yang cepat berubah. Misalnya, pembelajaran berbasis game (Connolly et al., 2012; Sousa \& Rocha, 2019), pembelajaran kooperatif (Azizan et al., 2018), pembelajaran berbasis masalah (Loyens et al., 2015), dan flipped classroom (Awidi \& Paynter, 2019) adalah beberapa contoh model pembelajaran aktif.

Dari contoh-contoh pembelajaran yang berpusat pada mahasiswa di atas, Flipped Classroom (FC) lebih menonjol terutama untuk fleksibilitas dan kemampuan beradaptasi ketika digunakan bersama-sama dengan metodologi pembelajaran aktif lainnya (Zainuddin, 2018). FC adalah metodologi pembelajaran aktif yang mendorong pemikiran tingkat tinggi dan partisipasi aktif dari siswa (Chen et al., 2017). Model FC mengusulkan penggunaan media campuran, di mana sumber daya virtual seperti video intruksional, teks buatan sendiri, atau materi pembelajaran multimedia lainnya digunakan untuk mengirimkan pengetahuan dan kelas tatap muka digunakan untuk mengkonsolidasikan pengetahuan melalui kegiatan interaktif, seperti pemecahan masalah, permainan peran, diskusi, dan kerja-kerja kolaboratif lainnya (Lo \& Hew, 2017). Beberapa karya ilmiah menunjukkan bahwa FC memiliki banyak manfaat dalam proses belajar mengajar. Misalnya, Fulton menyatakan bahwa mahasiswa dapat membuat kemajuan dalam memahami konten pembelajaran dengan kecepatan mereka 
sendiri (Lopes \& Soares, 2018). Selain itu, mengerjakan tugas di kelas memberikan kesempatan yang baik bagi dosen untuk merasakan kesulitan mahasiswa dan untuk melihat gaya belajar mereka yang berbeda. Hal ini memudahkan dosen dalam memodifikasi media dan konten pembelajaran sesuai dengan kebutuhan siswa dalam model ini. Dengan demikian, waktu dapat digunakan secara lebih efisien dan kreatif karena siswa memiliki kesempatan untuk belajar sendiri konten sebelum sesi tatap muka.

Studi tentang FC yang telah dikemukan menggunakan kelas tatap muka untuk mengkosolidasikan pengetahun, belum ada yang menggunakan kelas virtual. Oleh karena itu, penelitian ini mencoba menerapkan strategi FC melalui kelas virtual yang selanjutnya dinamakan Virtual Flipped Classroom (VFC) sebagai upaya mencari solusi terhadap permasalahan perkuliahan online. Pada penelitian ini, aspek yang dikaji adalah efek penerapan VFC terhadap motivasi dan kinerja kalkulus mahasiswa. Tujuannya adalah untuk mengetahui keefektifan metodologi pembelajaran VFC terhadap motivasi dan kinerja kalkulus mahasiswa.

\section{METODE PENELITIAN}

Penelitian ini termasuk dalam jenis penelitian kuantitatif. Untuk mengetahui pengaruh model VFC terhadap motivasi dan kinerja kalkulus mahasiswa, diberlakukan desain one group pretest-posttest design. Penelitian ini dikonseptualisasikan di Prodi Teknik Sipil Fakultas Sains dan Teknologi Universitas Sembilanbelas November Kolaka. Convenience sampling digunakan untuk memperoleh sampel penelitian dengan kriteria inklusi: memprogram Mata Kuliah Kalkulus I pada semester ganjil Tahun Akademik 2020. Sampel dari penelitian ini adalah kelas B berjumlah 28 orang. Sebuah tes awal (pretest) diberikan kepada peserta sebelum menerapkan VFC untuk mengukur kemampuan akademik awal mereka, dan selanjutnya diterapkan metode VFC.

Adapun tahapan model VFC yang diterapkan dalam penelitian ini dijelaskan sebagai berikut.

1. Tahap pra-kelas, yaitu waktu tiga hingga tujuh hari sebelum masuk jadwal perkuliahan. Pada tahap ini, konten pembelajaran berupa teks dan video dibagikan kepada mahasiswa melalui Google Classroom. Konten yang dibagikan mencakup tujuan pembelajaran, isi pelajaran, dan evaluasi. Lembar evaluasi dikerjakan oleh mahasiswa dan dikumpulkaan paling lambat 10 menit sebelum masuk kelas perkuliahan secara virtual. Ini bertujuan untuk menstimulus mahasiswa agar mempelajari dan memperdalam materi pembelajaran sebelum masuk kelas.

2. Tahap mulai kelas, yaitu waktu masuk jadwal perkuliahan. Tahap ini digunakan untuk mengeksplorasi dan mengkosolidasikan pengetahuan yang telah diperoleh mahasiswa saat pra-kelas melalui kegiatan interaktif, seperti diskusi, penyelesaian tugas, tutorial pemecahan masalah, game, dan kuis. Kegiatan pada tahap ini berlansung dalam kelas virtual melalui perpaduan aplikasi WA Grup, Google Classroom, dan Quizizz.

Percobaan berlansung selama setengah semester akademik, sebanyak tujuh kali pertemuan. Di akhir pertemuan, mahasiswa diberikan posttest untuk mengukur kinerja 
mahasiswa setelah diberikan perlakuan. Konten pembelajaran yang diproduksi dalam bentuk video mencakup tiga topik, yaitu (1) fungsi dan grafik fungsi; (2) limit dan kekontinuan; dan turunan fungsi. Sebanyak 15 video pembelajaran telah diproduksi dengan durasi waktu minimal 10 menit dan maksimal 20 menit setiap video. Setiap video membutuhkan empat tahap produksi berikut:

1. Perencanaan: tahap ini melibatkan pengenalan tujuan pembelajaran, menyiapkan konten pelajaran secara sempurna dengan berkonsentrasi pada kejelasan.

2. Rekaman: dalam tahap ini, perangkat lunak screen capture berbasis OBS digunakan untuk menghasilkan pelajaran video.

3. Pengeditan: tahap ini sangat penting dalam memastikan video mengalir sesuai dengan tujuan instruksional. Tujuannya adalah untuk meningkatkan video, dengan melibatkan penambahan rekaman, efek, musik atau grafik, judul, koreksi warna, atau menghilangkan rekaman yang tidak diinginkan.

4. Penerbitan: tahap terakhir bertujuan untuk mempublikasikan video pembelajaran secara aman ke platform online yaitu YouTube agar mudah diakses oleh mahasiswa secara berulang sesuai kebutuhan mereka.

Untuk memperoleh data kinerja kalkulus mahasiswa digunakan instrumen prestasi belajar berupa soal pilihan ganda yang terdiri dari 12 pertanyaan. Tes dilakukan secara online menggunakan aplikasi Quizizz. Enam puluh menit waktu dialokasikan untuk versi tes prestasi belajar. Instrument Survey of Student Motivation (SSM) merupakan instrumen kedua yang digunakan dalam penelitian ini. Tujuan utama dari instrumen SSM adalah untuk mengukur tingkat motivasi mahasiswa. SSM dirancang berdasarkan angket motivasi Keller (Keller, 2016), dengan beberapa adaptasi agar sesuai dengan tujuan penelitian. SSM dibagikan kepada peserta sebagai pretest dan posttest dalam bentuk formulir google. Angket terdiri dari 24 item yang dikategorikan menjadi empat bagian: Attention, Relevance, Confidence, and Satisfaction (ARCS). SSM diberikan kepada peserta selama 25 menit.

Data yang telah terkumpul selanjutnya dianalisis menggunakan metode deskriptif dan inferensial. Statistik deskriptif digunakan untuk menyajikan gambaran skor pretest dan posttest motivasi dan kinerja kalkulus mahasiswa melalui nilai mean dan standar deviasi. Untuk melihat kategori peningkatan skor posttest kinerja kalkulus mahasiswa dilakukan uji $\mathrm{N}$ gain (Meltzer dalam Ramadhani \& Amudi, 2020) dengan rumus 1 , sedangkan untuk Kriteria $\mathrm{N}$-gain disajikan pada Tabel 1 .

$$
N-\text { gain }(g)=\frac{\text { skor }_{\text {post }}-\text { skor }_{\text {pre }}}{\text { skor }_{\text {ideal }}-\text { skor }_{\text {pre }}}
$$

Tabel 1. Kriteria $N$-gain

\begin{tabular}{cc}
\hline $\boldsymbol{N}$-Gain $(\boldsymbol{g})$ & Kriteria \\
\hline $0,7 \leq g \leq 1$ & Tinggi \\
$0,3 \leq g<0,7$ & Sedang \\
$g<0,3$ & Rendah \\
\hline
\end{tabular}

Uji normalitas Shapiro Wilk dan homogenitas Lavene Test ikut disertakan sebagai uji asumsi sebelum melakukan analisis inferensial. Data pretest dan posttest dikatakan berdistribusi normal dan homogen jika hasil uji normalitas dan homogenitas masing-masing mempunyai nilai 
signifikansi > 0,05. Selanjutnya dilakukan uji Paired Sample T-Test untuk mengetahui apakah hasil pretest dan posttest kinerja kalkulus mahasiswa berbeda secara signifikan atau tidak. Berkenaan dengan tingkat motivasi, analisis varians multivariat satu arah (MANOVA) dilakukan dengan kelompok data (pretest dan posttest) sebagai faktor tetap dan attention, relevance, convidence, dan satisfaction sebagai variabel terikat. Semua analisis dilakukan dengan menggunakan software SPSS. Tingkat signifikansi statistik ditetapkan pada $\alpha=5 \%$.

\section{HASIL DAN PEMBAHASAN}

Motivasi belajar dianalisis menggunakan Survey of Student Motivation (SSM) yang dibagi menjadi empat variabel dependen (terikat), yaitu: Attention, Relevance, Convidence, dan Satisfaction (ARCS). Angket SSM diberikan kepada mahasiswa sebelum dan sesudah menerapkan model pembelajaran VFC. Gambaran mengenai Skor motivasi mahasiswa dideskripsikan pada Tabel 2 dan Gambar 1.

Tabel 2. Gambaran skor pretest dan posttest motivasi mahasiswa

\begin{tabular}{lcccccccc}
\hline \multirow{2}{*}{ Deskripsi } & \multicolumn{2}{c}{ Attention } & \multicolumn{2}{c}{ Relevance } & \multicolumn{2}{c}{ Convidence } & \multicolumn{2}{c}{ Satisfaction } \\
\cline { 2 - 9 } & Pre & Post & Pre & Post & Pre & Post & Pre & Post \\
\hline Mean & 2,96 & 3,61 & 2,84 & 3,78 & 2,52 & 3,38 & 2,51 & 3,15 \\
Standar Deviasi & 0,33 & 0,33 & 0.32 & 0.33 & 0,32 & 0,31 & 0,28 & 0,30 \\
Maksimum & 3,83 & 4,33 & 3,50 & 4,50 & 3,17 & 4,00 & 3,00 & 3,83 \\
Minimum & 2,17 & 2,83 & 2,33 & 3,17 & 2,00 & 2,67 & 2,00 & 2,67 \\
N & 28 & 28 & 28 & 28 & 28 & 28 & 28 & 28 \\
\hline
\end{tabular}

Berdasarkan Tabel 2 diperoleh bahwa skor rata-rata motivasi mahasiswa pada keempat variabel dependen yaitu attention, relevance, convidence, dan satisfaction mengalami peningkatan setelah diterapkan model pembelajaran VFC. Hal ini terlihat jelas pada Gambar 1, di mana grafik posttest berada di atas grafik pretest untuk semua aspek motivasi ARCS.

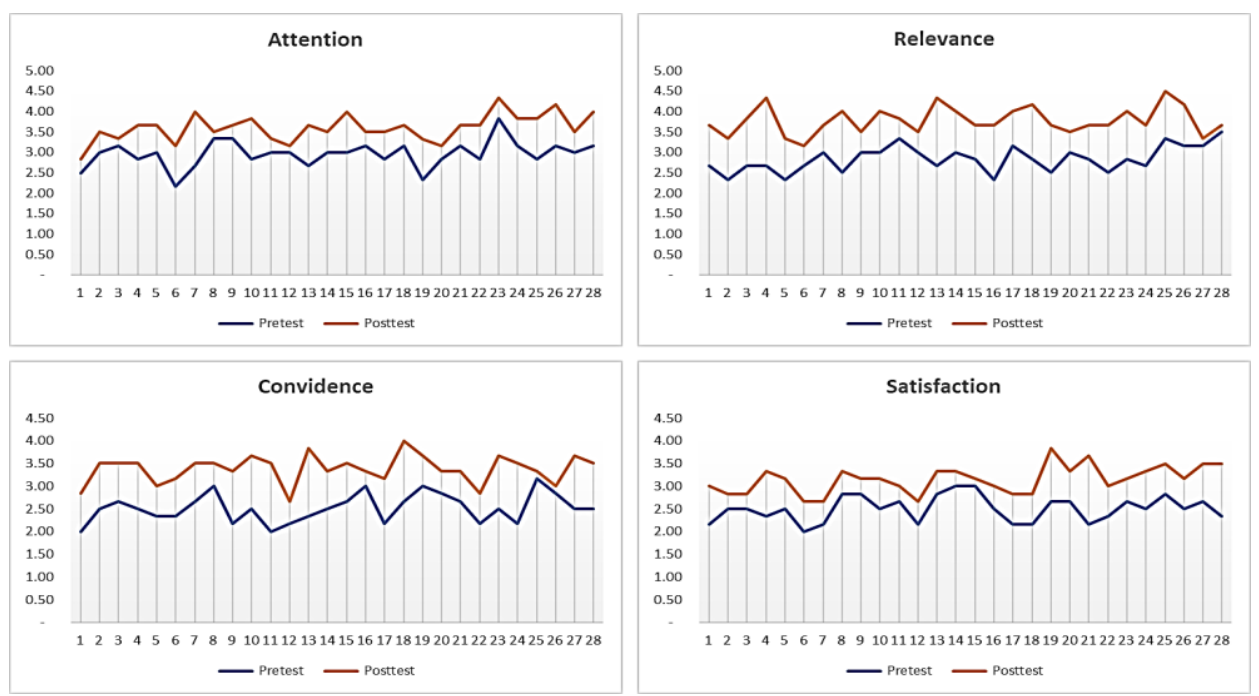

Gambar 1. Perbedaan skor pretest dan posttest motivasi mahasiswa 
Peningkatan skor motivasi mahasiswa ini selanjutnya dikonfirmasi dengan statistik inferensial berupa uji MANOVA satu arah. Hal ini bertujuan untuk mengetahui apakah skor pretest dan posttest berbeda secara signifikan atau tidak. Sebelum melakukan uji MANOVA, terlebih dahulu dilakukan Uji normalitas Shapiro Wilk dan homogenitas Lavene Test sebagai uji asumsi. Hasil uji normalitas dan homogenitas data motivasi mahasiswa berturut-turut disajikan pada Tabel 3 dan Tabel 4.

Tabel 3. Uji normalitas data motivasi menggunakan Shapiro Wilk

\begin{tabular}{lcc}
\hline \multicolumn{1}{c}{ Sumber Data } & Sig & Ket. \\
\hline Pre-Attention & 0,088 & Normal \\
Pre-Relevance & 0,353 & Normal \\
Pre-Convidence & 0,256 & Normal \\
Pre-Satisfaction & 0,127 & Normal \\
Post-Attention & 0,718 & Normal \\
Post-Relevance & 0,276 & Normal \\
Post-Convidence & 0,122 & Normal \\
Post-Satisfaction & 0,323 & Normal \\
\hline
\end{tabular}

Tabel 4. Uji homogenitas data motivasi menggunakan Lavene Test

\begin{tabular}{lcc}
\hline Sumber Data & Sig & Ket. \\
\hline Attention & 0,726 & Homogen \\
Relevance & 0,773 & Homogen \\
Convidence & 0,805 & Homogen \\
Satisfaction & 0,671 & Homogen \\
\hline
\end{tabular}

Tabel 3 menunjukkan bahwa nilai signifikansi untuk semua sumber data > 0,05 , sehingga dinyatakan berdistribusi normal. Demikian pula dengan uji homogenitas pada Tabel 4, nilai signifikansi > 0,05. Berdasarkan kriteria pengujian dengan SPSS, maka data dinyatakan homogen.

Selanjutnya dilakukan uji MANOVA dan ringkasan hasil ujinya disajikan pada Tabel 5.
Tabel 5. Uji MANOVA motivasi mahasiswa

\begin{tabular}{ccc}
\hline Motivasi & Jenis Tes & Sig \\
\hline \multirow{2}{*}{ Attention } & Pretest & 0,000 \\
& Posttest & 0,000 \\
\multirow{2}{*}{ Relevance } & Pretest & 0,000 \\
& Posttest & 0,000 \\
\multirow{2}{*}{ Convidence } & Pretest & 0,000 \\
& Posttest & 0,000 \\
\multirow{2}{*}{ Satisfaction } & Pretest & 0,000 \\
& Posttest & 0,000 \\
\hline
\end{tabular}

Berdasarkan hasil uji MANOVA Tabel 5, diperoleh nilai signifikansi 0,000 yang lebih kecil dari nilai $\alpha$ yang ditetapkan yaitu 0,05 untuk semua aspek motivasi. Hal ini mengkonfirmasi hasil statistik deskriptif bahwa peningkatan skor motivasi setelah diterapkan model pembelajaran VFC adalah signifikan. Peningkatan ini dapat dijelaskan karena model pembelajaran VFC yang mengintegrasikan model VC dan FC dapat mengurangi tingkat stress dan meningkatkan perasaan positif mahasiswa dalam kaitannya dengan pembelajaran kalkulus. Ini terlihat jelas dalam upaya mahasiswa untuk menjawab pertanyaan evaluasi formatif yang diajukan dalam video pembelajaran maupun teks bacaan dan dalam pertanyaan mereka yang muncul setelah menonton pelajaran video.

Mahasiswa termotivasi untuk menjawab pertanyaan melalui kegiatan kolaboratif tanpa ada tekanan teman sebaya. Hasil tersebut mendukung temuan penelitian sebelumnya (Marlowe, 2012) bahwa interaksi sosial selama VC berdampak positif terhadap motivasi belajar siswa dan berkontribusi pada keberhasilan belajar. Antusiasme, interaksi, dan kolaborasi terlihat pada semua pertemuan virtual di VC, baik interaksi antara mahasiswa maupun dengan dosen. 
Hasil penelitian ini juga relevan dengan (Martínez-Jiménez \& RuizJiménez, 2020; Murillo-Zamorano et al., 2019; Goh \& Ong, 2019) yang menyimpulkan bahwa metodologi Flipped Classroom (FC) secara signifikan meningkatkan dimensi afektif-emosional mahasiswa, dengan meningkatkan minat, motivasi dan partisipasi aktif dalam kegiatan pembelajaran. Melalui metode FC dosen memiliki kesempatan yang cukup untuk merasakan kesulitan mahasiswa dan untuk melihat gaya belajar mereka yang berbeda. Hal ini memudahkan dosen dalam memodifikasi media dan konten pembelajaran sesuai dengan kebutuhan mahasiswa.

Kinerja kalkulus mahasiswa diukur menggunakan tes prestasi belajar yang diberikan kepada mahasiswa sebagai pretest dan posttest. Deskripsi hasil pretest dan posttest disajikan pada Tabel 5 dan Gambar 2.

Tabel 5. Deskripsi pretest dan posttest prestasi belajar mahasiswa

\begin{tabular}{lcc} 
Deskripsi & Pretest & Posttest \\
\hline Mean & 49,11 & 76,49 \\
Standar Deviasi & 15,27 & 12,01 \\
Maksimum & 91,67 & 100,00 \\
Minimum & 25,00 & 58,33 \\
N & 28 & 28 \\
\hline
\end{tabular}

Dari Tabel 5 terlihat bahwa ada perbedaan rata-rata prestasi belajar mahasiswa pada pretest (sebelum penerapan model VFC) dan posttest (setelah penerapan model VFC). Ratarata prestasi belajar mahasiswa pada pretest adalah 49,11 dengan standar deviasi 15,27 sedangkan pada posttest, rata-ratanya meningkat menjadi 76,49 dengan standar deviasi 12,01. Standar deviasi pada kedua jenis tes tersebut menunjukkan bahwa sebaran prestasi belajar mahasiswa setelah penerapan model VFC cenderung lebih dekat dengan nilai rata-rata dibandingkan dengan sebelum penerapan model VFC.

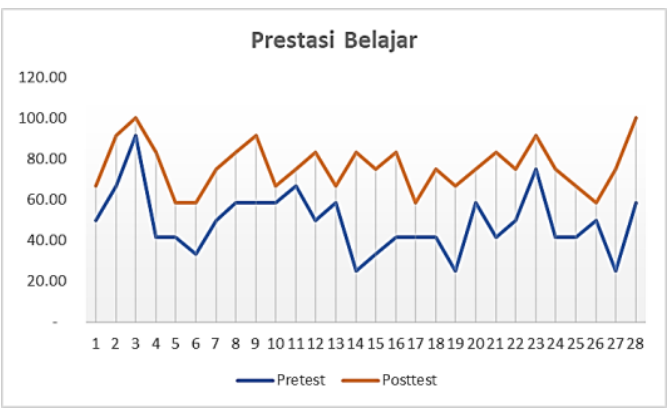

Gambar 2. Gambaran prestasi belajar mahasiswa pada pretest dan posttest

Peningkatan skor posttest kinerja kalkulus mahasiswa selanjutnya dikategorikan berdasarkan kriteria $\mathrm{N}$ gain yang disajikan pada Tabel 6 .

Tabel 6. Jumlah mahasiswa berdasarkan kriteria $\mathrm{N}$-gain

\begin{tabular}{cc}
\hline Kriteria N-gain & $\begin{array}{c}\text { Jumlah } \\
\text { mahasiswa }\end{array}$ \\
\hline Tinggi & 8 \\
Sedang & 14 \\
Rendah & 6 \\
\hline
\end{tabular}

Berdasrkan Tabel 6 dapat dijelaskan bahwa skor posttest kinerja kalkulus mahasiswa meningkat dengan sebaran 8 orang atau 28,57\% memperoleh kriteria tinggi, 14 orang atau $50 \%$ kriteria sedang dan 6 orang atau $21,43 \%$ kriteria rendah. Jika dirataratakan maka peningkatan skor berada pada kriteria sedang sedang skor ratarata 0,55 .

Selanjutnya statistik inferensial berupa paired sample t-test digunakan untuk mengecek efektifitas model pembelajaran VFC atau untuk mengetahui keberartian peningkatan kinerja kalkulus mahasiswa setelah penerapan model pembelajaran VFC. Uji normalitas Shapiro Wilk dan uji homogenitas Lavene Test turut 
disertakan sebagai uji asumsi sebelum melakukan uji t (paired sample t-test). Berikut disajikan ringkasan uji normalitas data dan homogenitas data secara berturut-turut pada Tabel 7 dan Tabel 8.

Tabel 7. Uji normalitas data prestasi belajar menggunakan Shapiro Wilk

\begin{tabular}{lcc}
\hline Sumber Data & Sig & Ket. \\
\hline Pretest & 0,112 & Normal \\
Posttest & 0,095 & Normal \\
\hline
\end{tabular}

Tabel 8. Uji homogenitas data prestasi belajar menggunakan Lavene Test

\begin{tabular}{lcc}
\hline Sumber Data & Sig & Ket. \\
\hline Prestasi belajar & 0,349 & Homogen \\
\hline
\end{tabular}

Berdasarkan Tabel 7 dan Tabel 8 diperoleh nilai sig > 0,05. Dengan demikian dapat disimpulkan bahwa data berdistribusi normal dan homogen. Uji paired sample t-test disajikan pada Tabel 9.

Tabel 9. Uji paired sample t test pretest dan posttest prestasi belajar

\begin{tabular}{cccc}
\hline $\begin{array}{c}\text { Sumber } \\
\text { Data }\end{array}$ & $\begin{array}{c}\text { Std } \\
\text { Dev }\end{array}$ & t & Sig \\
\hline $\begin{array}{c}\text { Pretest } \\
\text { Posttest }\end{array}$ & 16,31 & $-8,498$ & 0,000 \\
\hline
\end{tabular}

Nilai probabilitas $(\mathrm{Sig})=0,000$ pada hasil uji Tabel 9 menunjukkan bahwa terdapat perbedaan yang signifikan antara skor rata-rata pretest (sebelum penerapan VFC) dengan skor rata-rata posttest (setelah penerapan VFC). Perbedaan skor tersebut berupa adanya peningkatan kinerja kalkulus mahasiswa setelah penerapan model pembelajaran VFC yang berada pada kategori sedang sebagaiman terkonfirmasi pada hasil uji $\mathrm{N}$-gain.

Penerapan model pembelajaran VFC telah mendukung pembelajaran dan pemahaman mahasiswa melalui video pembelajaran yang dibagikan kepada mahasiswa di waktu pra-kelas melalui aplikasi Google Classroom. Hasil ini relevan dengan penelitian sebelumnya (Thai et al., 2017) bahwa model FC memungkinkan instruktur membagikan video pembelajaran kepada mahasiswa dalam kelas virtual pada waktu tiga hingga tujuh hari sebelum masuk waktu perkuliahan. Hal ini akan memberikan kesempatan yang baik kepada mahasiswa untuk menyimak dan memahami konten pembelajaran secara berulang sesuai yang mereka butuhkan. Sehingga saat masuk jadwal perkuliahan, mahasiswa sudah memiliki pengetahuan awal yang siap untuk dieksplorasi melalui kegiatan konsolidasi pemahaman berupa diskusi terbuka, tutorial pemecahan masalah, dan kegiatan-kegiatan kolaboratif lainnya.

Selain itu, manfaat yang bisa dirasakan oleh mahasiswa melalui penggunaan model VC adalah mahasiswa dapat merekam dan mengulang setiap bagian dari kuliah virtual (O'Callaghan et al., 2017). Ini secara khusus membantu mahasiswa mengulang jawaban dosen atas pertanyaan mereka yang mungkin tidak terjawab selama tahap pra-kelas dalam model VFC.

Penelitian ini menemukan bahwa implementasi strategi Virtual Flipped Classtoom (VFC) pada perkuliahan kalkulus berefek postif terhadap peningkatan motivasi dan kinerja akademik mahasiswa. Hal ini dapat dijelaskan karena konten pembelajaran multimedia yang dibagikan kepada mahasiswa pada waktu pra-kelas, yaitu tiga hingga tujuh hari sebelum masuk jadwal perkuliahan dapat menggerakkan mahasiswa untuk mempelajari materi melalui kegiatan membaca maupun menyimak dan menonton video. 
Feedback yang diikutsertakan pada setiap konten pembelajaran mengharuskan mahasiswa untuk mempelajari terlebih dahulu agar bisa mengerjakannya dan hasil pekerjaan mahasiswa sekaligus menjadi prasyarat untuk ikut kuliah. Waktu pada kelas virtual dimanfatkan untuk presentasi mahasiswa terhadap tugas atau feedback yang dikerjakan pada waktu pra-kelas untuk selanjutnya didiskusikan. Hasil penelitian ini mendukung temuan sebelumnya bahwa strategi flipeed classroom dapat memotivasi mahasiswa untuk mengarahkan pembelajarannya dan mengembangkan serangkaian keterampilan inti yang saling terkait, seperti pemecahan masalah, kelancaran, fleksibilitas, antisipasi, memasukkan ide ke dalam konteks, dan merefleksikan berbagai perspektif yang meningkatkan kinerja akademik (Zainuddin, 2018; Khanova et al., 2015; Marlowe, 2012).

Implikasi teoritis dari penelitian ini adalah penggunaan strategi atau pendekatan pembelajaran online yang tepat. Dalam hal ini memahami kebutuhan mahasiswa serta penggunaan media pembelajaran yang interaktif dapat berpengaruh pada keberhasilan karir akademik mahasiswa. Secara praktis, hasil penelitian ini dapat menjadi bahan rujukan dalam merencanakan dan mengelola pembelajaran secara online guna meningkatkan kinerja akademik mahasiswa.

\section{KESIMPULAN DAN SARAN}

Hasil penelitian menunjukkan bahwa model pembelajaran Virtual Flipped Classroom (VFC) efektif terhadap motivasi dan kinerja kalkulus mahasiswa. Penerapan VFC telah teruji meningkatkan motivasi dan kinerja kalkulus mahasiswa dengan kriteria peningkatan sedang. Oleh karena itu,
Model VFC dapat menjadi salah satu pilihan strategis dalam pembelajaran jarak jauh terutama dimasa pandemik Covid-19. Penerapan model VFC dapat diperluas untuk topik-topik lain serta dengan subjek yang berbeda dan tempat yang berbeda pula.

Hasil penelitian ini dapat menjadi tambahan referensi bagi penelitian selanjutnya untuk mengkaji lebih dalam lagi mengenai efektefitas model VFC dalam meningkatkan partisipasi aktif siswa dalam proses pembelajaran online dan hasil belajar untuk topik materi yang lain, terutama untuk materi yang sifatnya abstrak.

\section{DAFTAR PUSTAKA}

Ario, M., \& Asra, A. (2018). Pengaruh Pembelajaran Flipped Classroom terhadap Hasil Belajar Kalkulus Integral Mahasiswa Pendidikan Matematika. ANARGYA: Jurnal Ilmiah Pendidikan Matematika, 1(2), 82-88. https://doi.org/10.24176/anargya.v $1 \mathrm{i} 2.2477$

Awidi, I. T., \& Paynter, M. (2019). The impact of a flipped classroom approach on student learning experience. Computers and Education.

https://doi.org/10.1016/j.compedu. 2018.09.013

Azizan, M. T., Mellon, N., Ramli, R. M., \& Yusup, S. (2018). Improving teamwork skills and enhancing deep learning via development of board game using cooperative learning method in Reaction Engineering course. Education for Chemical Engineers. https://doi.org/10.1016/j.ece.2017. 10.002

Chen, F., Lui, A. M., \& Martinelli, S. M. (2017). A systematic review of the effectiveness of flipped 
classrooms in medical education. In Medical Education. https://doi.org/10.1111/medu.1327 2

Connolly, T. M., Boyle, E. A., MacArthur, E., Hainey, T., \& Boyle, J. M. (2012). A systematic literature review of empirical evidence on computer games and serious games. Computers and Education.

https://doi.org/10.1016/j.compedu. 2012.03.004

Goh, C. F., \& Ong, E. T. (2019). Flipped classroom as an effective approach in enhancing student learning of a pharmacy course with a historically low student pass rate. Currents in Pharmacy Teaching and Learning, 11(6), 621-629. https://doi.org/10.1016/j.cptl.2019. 02.025

Keller, J. M. (2016). Motivation, Learning, and Technology: Applying the ARCS-V Motivation Model. Participatory Educational Research.

https://doi.org/10.17275/per.16.06. 3.2

Khanova, J., McLaughlin, J. E., Rhoney, D. H., Roth, M. T., \& Harris, S. (2015). Student perceptions of a flipped pharmacotherapy course. American Journal of Pharmaceutical Education.

https://doi.org/10.5688/ajpe799140

Lee, A. (2011). A comparison of postsecondary science, technology, engineering, and mathematics (stem) enrollment for students with and without disabilities. Career Development for Exceptional Individuals, 34(2), 72-82. https://doi.org/10.1177/088572881 0386591

Lo, C. K., \& Hew, K. F. (2017). A critical review of flipped classroom challenges in K-12 education: possible solutions and recommendations for future research. In Research and Practice in Technology Enhanced Learning. https://doi.org/10.1186/s41039016-0044-2

Lo, C. K., Hew, K. F., \& Chen, G. (2017). Toward a set of design principles for mathematics flipped classrooms: A synthesis of research in mathematics education. Educational Research Review, 22, 50-73.

https://doi.org/10.1016/j.edurev.20 17.08.002

Lopes, A. P., \& Soares, F. (2018). Perception and performance in a flipped Financial Mathematics classroom. International Journal of Management Education, 16(1), 105-113.

https://doi.org/10.1016/j.ijme.2018 .01 .001

Loyens, S. M. M., Jones, S. H., Mikkers, J., \& van Gog, T. (2015). Problem-based learning as a facilitator of conceptual change. Learning and Instruction. https://doi.org/10.1016/j.learninstr uc. 2015.03.002

Marlowe, C. A. (2012). THE EFFECT OF THE FLIPPED CLASSROOM ON STUDENT ACHIEVEMENT AND STRESS. Journal of Chemical Information and Modeling.

Martínez-Jiménez, R., \& Ruiz-Jiménez, M. C. (2020). Improving students' satisfaction and learning performance using flipped classroom. International Journal of Management Education. https://doi.org/10.1016/j.ijme.2020 .100422

Murillo-Zamorano, L. R., López 
Sánchez, J. Á., \& GodoyCaballero, A. L. (2019). How the flipped classroom affects knowledge, skills, and engagement in higher education: Effects on students' satisfaction. Computers and Education, 141(June). https://doi.org/10.1016/j.compedu. 2019.103608

O'Callaghan, F. V., Neumann, D. L., Jones, L., \& Creed, P. A. (2017). The use of lecture recordings in higher education: A review of institutional, student, and lecturer issues. Education and Information Technologies.

https://doi.org/10.1007/s10639-

015-9451-z

Pearson, W., \& Miller, J. D. (2012). Pathways to an Engineering Career. Peabody Journal of Education, 87(1), 46-61. https://doi.org/10.1080/0161956X. 2012.642270

Pelger, S., \& Nilsson, P. (2018). Observed learning outcomes of integrated communication training in science education: skills and subject matter understanding. International Journal of Science Education, Part B: Communication and Public Engagement, 8(2). https://doi.org/10.1080/21548455.2 017.1417653

Ramadhani, R., \& Amudi, A. (2020). EFEKTIFITAS PENGGUNAAN MODUL MATEMATIKA

DASAR PADA MATERI BILANGAN TERHADAP HASIL BELAJAR. AKSIOMA: Jurnal Program Studi Pendidikan Matematika, 9(1). https://doi.org/10.24127/ajpm.v9i1.
2443

Schwarzenberg, P., Navon, J., Nussbaum, M., Pérez-Sanagustín, M., \& Caballero, D. (2018). Learning experience assessment of flipped courses. Journal of Computing in Higher Education. https://doi.org/10.1007/s12528017-9159-8

Shodikin, A. (2017). Pengembangan Bahan Ajar Kalkulus Integral Berbasis Animasi. AKSIOMA: Jurnal Program Studi Pendidikan Matematika, 6(1), 1. https://doi.org/10.24127/ajpm.v6i1. 887

Sousa, M. J., \& Rocha, Á. (2019). Leadership styles and skills developed through game-based learning. Journal of Business Research.

https://doi.org/10.1016/j.jbusres.20 18.01.057

Thai, N. T. T., De Wever, B., \& Valcke, M. (2017). The impact of a flipped classroom design on learning performance in higher education: Looking for the best "blend" of lectures and guiding questions with feedback. Computers and Education.

https://doi.org/10.1016/j.compedu. 2017.01.003

Zainuddin, Z. (2018). Students' learning performance and perceived motivation in gamified flippedclass instruction. Computers and Education.

https://doi.org/10.1016/j.compedu. 2018.07.003 